\title{
The Effects of Hydrophobicity and Textural Properties on Hexamethyldisiloxane Adsorption in Reduced Graphene Oxide Aerogels
}

\author{
Xifeng Hou ${ }^{1} \mathbb{D}$, Yanhui Zheng ${ }^{1,2}$, Xiaolong Ma ${ }^{3}$, Yuheng Liu ${ }^{4}$ and Zichuan Ma ${ }^{1, * \mathbb{C}}$ \\ 1 Hebei Key Laboratory of Inorganic Nano-Materilas, College of Chemistry and Material Science, \\ Hebei Normal University, Shijiazhuang 050024, Hebei, China; xifenghoucc@163.com (X.H.); \\ zhengyh0308@163.com (Y.Z.) \\ 2 Shijiazhuang Vocational College of Finance \& Economics, Shijiazhuang 050061, Hebei, China \\ 3 School of Environmental Science and Engineering, Hebei University of Science and Technology, \\ Shijiazhuang 050018, Hebei, China; maxiaolong2410@163.com \\ 4 College of Pharmaceutical Sciences, Hebei Medical University, Shijiazhuang 050017, Hebei, China; \\ liu2795478@163.com \\ * Correspondence: mazc@hebtu.edu.cn; Tel.: +86-311-8078-7400
}

Citation: Hou, X.; Zheng, Y.; Ma, X.; Liu, Y.; Ma, Z. The Effects of

Hydrophobicity and Textural

Properties on Hexamethyldisiloxane Adsorption in Reduced Graphene Oxide Aerogels. Molecules 2021, 26, 1130. https://doi.org/10.3390/ molecules26041130

Academic Editor: Dipendu Saha

Received: 15 January 2021

Accepted: 17 February 2021

Published: 20 February 2021

Publisher's Note: MDPI stays neutral with regard to jurisdictional claims in published maps and institutional affiliations.

Copyright: (c) 2021 by the authors. Licensee MDPI, Basel, Switzerland. This article is an open access article distributed under the terms and conditions of the Creative Commons Attribution (CC BY) license (https:// creativecommons.org/licenses/by/ $4.0 /)$.

\begin{abstract}
To expand the applications of graphene-based materials to biogas purification, a series of reduced graphene oxide aerogels (rGOAs) were prepared from industrial grade graphene oxide using a simple hydrothermal method. The influences of the hydrothermal preparation temperature on the textural properties, hydrophobicity and physisorption behavior of the rGOAs were investigated using a range of physical and spectroscopic techniques. The results showed that the rGOAs had a macro-porous three-dimensional network structure. Raising the hydrothermal treatment temperature reduced the number of oxygen-containing groups, whereas the specific surface area $\left(S_{\mathrm{BET}}\right)$, micropore volume $\left(V_{\text {micro }}\right)$ and water contact angle values of the rGOAs all increased. The dynamic adsorption properties of the rGOAs towards hexamethyldisiloxane (L2) increased with increasing hydrothermal treatment temperature and the breakthrough adsorption capacity showed a significant linear association with $S_{\mathrm{BET}}, V_{\text {micro }}$ and contact angle. There was a significant negative association between the breakthrough time and inlet concentration of L2, and the relationship could be reliably predicted with a simple empirical formula. L2 adsorption also increased with decreasing bed temperature. Saturated rGOAs were readily regenerated by a brief heat-treatment at $100^{\circ} \mathrm{C}$. This study has demonstrated the potential of novel rGOA for applications using adsorbents to remove siloxanes from biogas.
\end{abstract}

Keywords: reduced graphene oxide aerogel; hexamethyldisiloxane; adsorption; hydrophobicity; siloxane

\section{Introduction}

Biogas is an alternative energy source produced by the anaerobic digestion of organic material. It can be produced from raw materials such as agricultural, food and municipal waste products, and sewage sludge [1,2]. Due to its relatively high methane content and calorific value, biogas has been widely investigated as a renewable energy source for heating and power generation $[3,4]$. However, siloxanes, present at low concentrations in biogas, can compromise the operation of biogas-to-energy facilities, presenting technical challenges for its widespread use [5]. During combustion, siloxanes such as hexamethyldisiloxane (L2) and octamethylcyclotetrasiloxane (D4) can form white deposits $\left(\mathrm{SiO}_{2}\right)$ on critical components, decreasing their performance and increasing the costs of maintenance and operation [6,7]. Consequently, amounts of siloxanes in biogas must be reduced below threshold levels (e.g., $10 \mathrm{mg}$ siloxane $/ \mathrm{m}^{3}$ of methane) prior to use in energy applications [8-10]. 
Materials currently used to reduce siloxanes in biogas include high efficiency adsorbents such as activated carbon, silica and molecular sieves [5,11-13]. While these adsorbents are relatively low cost, simple to use [14-16] and high in adsorption capacity, their adsorption cycle performances are limited, restricting their practical applications. Previously, we developed a modified silica gel siloxane adsorbent with good recyclability and found that its adsorption performance was affected by its textural properties, such as the specific surface area $\left(S_{\mathrm{BET}}\right)$, total pore volume $\left(V_{\text {tot }}\right)$, micropore volume $\left(V_{\text {micro }}\right)$ and contact angle [16-18]. Reduced graphene oxide aerogels (rGOAs) have good textural properties and strong hydrophobicity [19-26], although their application to biogas siloxane removal has not been reported. In addition, rGOAs were prepared using commercially available industrial grade graphene oxide (IGGO) without any reducing agents. Compared with traditional preparation methods [25], this strategy is simple, low cost, flexible, versatile, readily scalable and insensitive to environmental conditions.

Hence, the aims of this study were to develop a novel siloxane adsorbent based on readily obtained rGOAs for the purification of biogas, and determine the key factors affecting its performance. An understanding of these factors will assist the future design of rGOAs for gas phase dynamic adsorption applications.

\section{Results and Discussion}

\subsection{Effects of Hydrothermal Temperature on Texture Properties and Hydrophobicity}

The hydrothermal preparation process is illustrated in Figure 1 for rGOA-200. The procedure involved three main steps: (1) sonication to obtain a $10 \mathrm{mg} \cdot \mathrm{L}^{-1}$ IGGO precursor dispersion ( $\mathrm{pH}=7.0$ ); (2) partial hydrothermal reduction of oxygen-containing functional groups distributed on the IGGO surface and promotion of rGO sheet self-assembly into the rGO hydrogel; (3) lyophilization to minimize the capillary force and achieve the rGOA three-dimensional (3D) network structure [27-29]. The hydrothermal synthesis temperature was believed to be a significant factor affecting the textural properties and hydrophobicity of rGOA materials [27,30-32]. Figure 2 shows the $\mathrm{N}_{2}$ adsorption-desorption isotherms of IGGO and two representative rGOA composites (i.e., rGOA-120 and rGOA-200). The calculated textural parameters from the $\mathrm{N}_{2}$ physisorption measurements of these materials are listed in Table 1. The shapes of the gas adsorption isotherms for rGOAs were consistent with IUPAC type $\mathrm{V}$ curves with a type $\mathrm{H} 3$ hysteresis loop $[8,33]$. The shapes of $\mathrm{N}_{2}$ adsorption-desorption isotherms were slightly increased at low relative pressures $\left(P / P_{0}<0.4\right)$ and sharply increased at high relative pressure $\left(0.93<P / P_{0}<1.0\right)$, indicating the coexistence of slotted mesopores and macropores [16,34]. Compared with rGOAs, IGGO had a significantly smaller $\mathrm{N}_{2}$ adsorption volume and exhibited a type III isotherm, reflecting its relatively non-porous/macroporous structure [35].
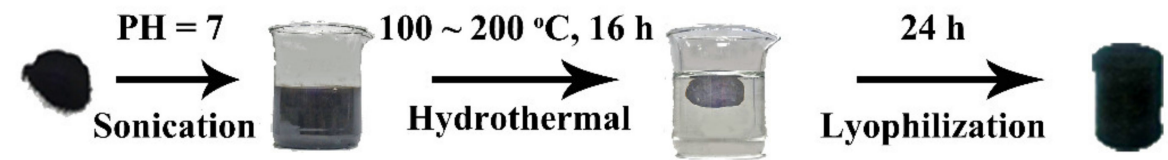

Figure 1. Illustration of the preparation process of the reduced graphene oxide aerogel (rGOA).

Table 1 shows that $\mathrm{D}_{\text {aver }}$ was reduced while $S_{\mathrm{BET}}$ and $V_{\text {micro }}$ both increased with increasing hydrothermal temperature. This monotonic behavior was not observed for $V_{\text {tot, }}$ which reached a maximum value of $0.45 \mathrm{~cm}^{3} \cdot \mathrm{g}^{-1}$ for rGOA-140, indicating that the 3D macroscopic assemblies of rGOA had a mesoporous/macroporous texture [16,22].

Figure 3 shows the contact angle analysis diagram for rGOA-200 demonstrating a hydrophobic surface [36,37]. The contact angle, and hence the hydrophobicity, increased with increasing hydrothermal temperature for all rGOAs (see Table 1). 


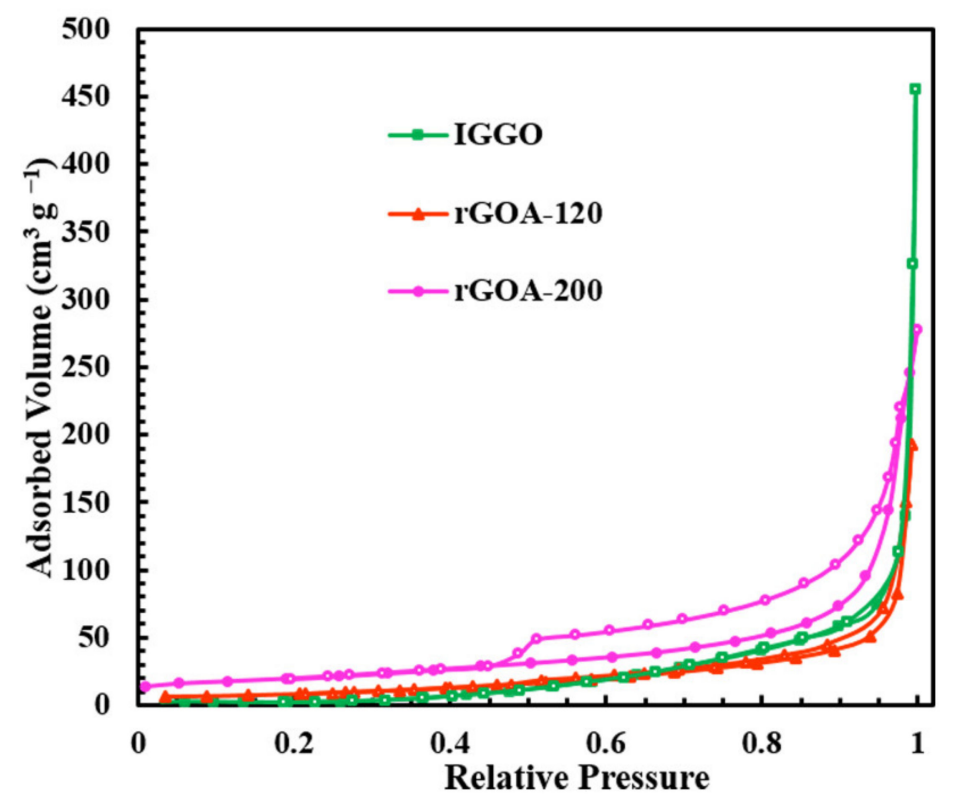

Figure 2. $\mathrm{N}_{2}$ adsorption-desorption isotherms.

Table 1. Textural properties and contact angles of the materials.

\begin{tabular}{cccccc}
\hline Adsorbent & $\boldsymbol{S}_{\mathbf{B E T}}, \mathbf{m}^{\mathbf{2}} \cdot \mathbf{g}^{-\mathbf{1}}$ & $\begin{array}{c}\boldsymbol{V}_{\text {micro, }} \\
\mathbf{c m}^{\mathbf{3}} \cdot \mathbf{g}^{\mathbf{- 1}}\end{array}$ & $\begin{array}{c}\boldsymbol{V}_{\text {tot, }} \\
\mathbf{c m}^{\mathbf{3}} \cdot \mathbf{g}^{-\mathbf{1}}\end{array}$ & $\mathbf{D}_{\text {aver, }} \mathbf{n m}$ & Contact Angle, $^{\circ}$ \\
\hline IGGO & 7.4 & 0.011 & 0.23 & 124.3 & $76.6 \pm 0.4$ \\
rGOA-100 & 10.7 & 0.010 & 0.19 & 71.0 & $118.1 \pm 0.2$ \\
rGOA-120 & 36.7 & 0.014 & 0.26 & 28.3 & $119.9 \pm 0.3$ \\
rGOA-140 & 59.0 & 0.021 & 0.45 & 30.5 & $123.5 \pm 0.3$ \\
rGOA-160 & 61.4 & 0.024 & 0.32 & 20.9 & $124.2 \pm 0.3$ \\
rGOA-200 & 79.6 & 0.031 & 0.39 & 19.6 & $128.7 \pm 0.6$ \\
\hline
\end{tabular}

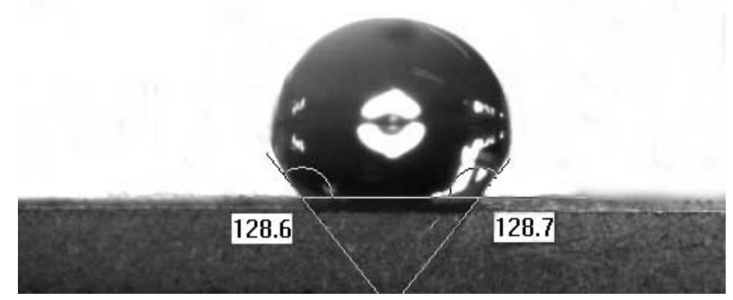

Figure 3. Image showing a water droplet on the surface of an rGOA-200 film.

\subsection{XRD, SEM, TEM, Raman, Elemental and FTIR Analysis of rGOAs and IGGO}

Figure 4 shows the XRD patterns obtained from IGGO, rGOA-120 and rGOA-200. The sharp peak at $2 \theta=11.6^{\circ}$ (IGGO), corresponding to the (001) plane with an interlayer spacing (d-spacing) of $0.76 \mathrm{~nm}$, was typical of the separation between the layered IGGO sheets [38]. The absence of this peak for both rGOA-120 and rGOA-200, and the appearance of a new peak at $\approx 24^{\circ}\left(\mathrm{d}_{002}\right.$ of ca. $\left.0.37 \mathrm{~nm}\right)$, are both consistent with the combining of graphene sheet structures during a hydrothermal reduction [30,39]. 


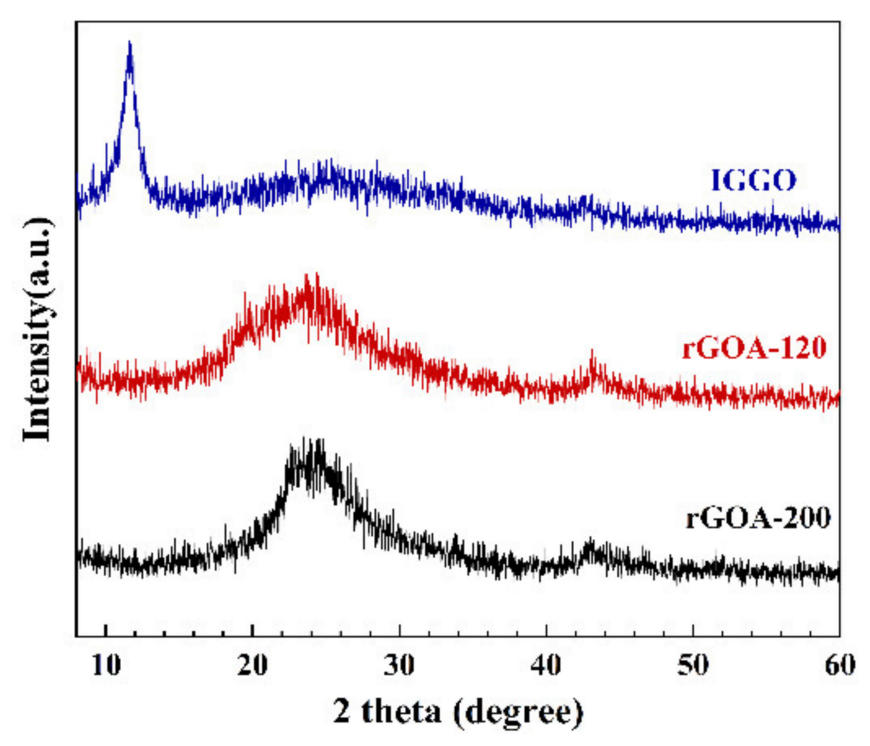

Figure 4. XRD patterns of the materials.

The SEM images of IGGO and the two typical rGOA samples are given in Figure 5a-f. Compared with IGGO, the rGOAs exhibited a rich macroporous 3D network structure and more slit-like pores. Furthermore, TEM images of IGGO and rGOA-200 (Figure S1, Supplementary Materials) illustrate the overlapping of transparent graphene nanosheets with many wrinkles. IGGO had overlaps of multiple layers, whereas rGOA-200 exhibited only a few layers after hydrothermal reduction. This morphology is also consistent with the $\mathrm{N}_{2}$ adsorption-desorption isotherm results. The Raman spectra of IGGO and the two typical rGOA samples are given in Figure 6. The peaks located in the range of $2600-2800 \mathrm{~cm}^{-1}$ are the $2 \mathrm{D}$ bands, which are another characteristic peak of graphene [40]. The rGOA showed a fairly broad and up-shift 2D peak in the Raman spectrum, indicating its few-layer structure, which was consistent with the TEM results. The increased ratio of the $\mathrm{I}_{\mathrm{D}} / \mathrm{I}_{\mathrm{G}}$ bands for rGOA-120 and rGOA-200 indicated that these structures were more disordered compared to IGGO [37,40]. In general, the characteristic D $\left(1350 \mathrm{~cm}^{-1}\right)$ and $\mathrm{G}\left(1590 \mathrm{~cm}^{-1}\right)$ bands in the Raman spectra of graphite-based materials can be attributed to the lattice defects and the in-plane stretching vibrations of $\mathrm{sp}^{2}$ hybridized atoms [41]. The increase in $\mathrm{I}_{\mathrm{D}} / \mathrm{I}_{\mathrm{G}}$ from IGGO $\rightarrow$ rGOA was also consistent with removal of the oxygen-containing moieties present in IGGO, and their removal was temperature dependent. These observations can be further confirmed by the element analysis results (Table S1, Supplementary Materials). The oxygen content in both rGOA-120 and rGOA-200 materials was significantly diminished in comparison with IGGO, and rGOA-200 had less oxygen content than rGOA-120. The changes to oxygen-containing groups in IGGO with hydrothermal temperature treatment could be observed in the normalized FTIR spectra of IGGO, rGOA-120 and rGOA-200 shown in Figure 7. The intensities of the stretching vibration peaks at $1720 \mathrm{~cm}^{-1}$ (carbonyl and carboxyl groups) and peaks at $3450 \mathrm{~cm}^{-1}$ (-OH stretching vibration) and $1400 \mathrm{~cm}^{-1}$ (-OH bending vibration) all decreased in the order IGGO > rGOA-120 > rGOA-200 [19]. Similarly, the characteristic band at $1040 \mathrm{~cm}^{-1}$ (C-O bending vibration) weakened in the order IGGO $>$ rGOA-120 > rGOA-200, indicating partial cleavage of $\mathrm{C}-\mathrm{O}$ bonds during the hydrothermal reduction. In addition, the intensities of the characteristic stretching vibrations at $1640 \mathrm{~cm}^{-1}$ ( $\mathrm{C}=\mathrm{C}$ group) for both rGOA samples were significantly increased [42], which is indicative of the restoration of the $\pi$-conjugation network of graphene following a hydrothermal reduction [43]. 


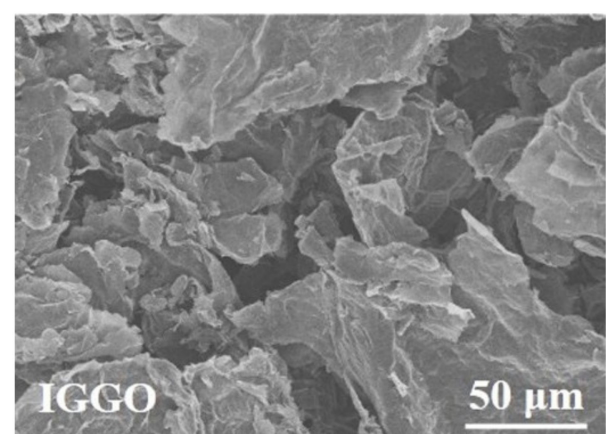

(a)

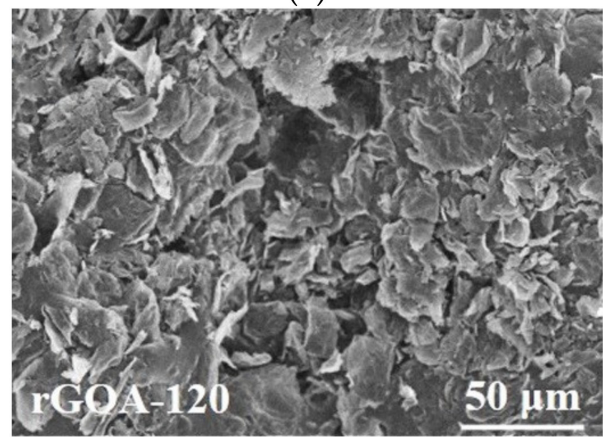

(c)

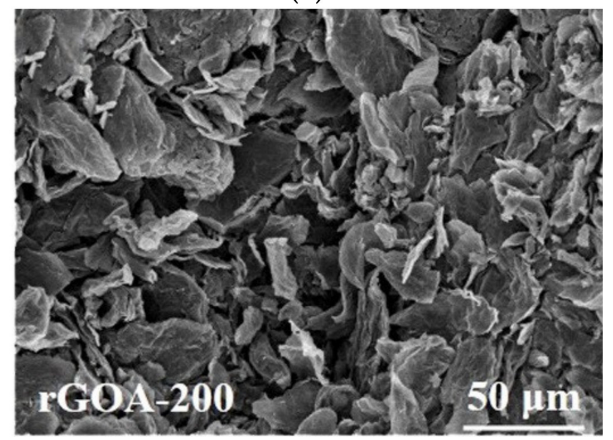

(e)

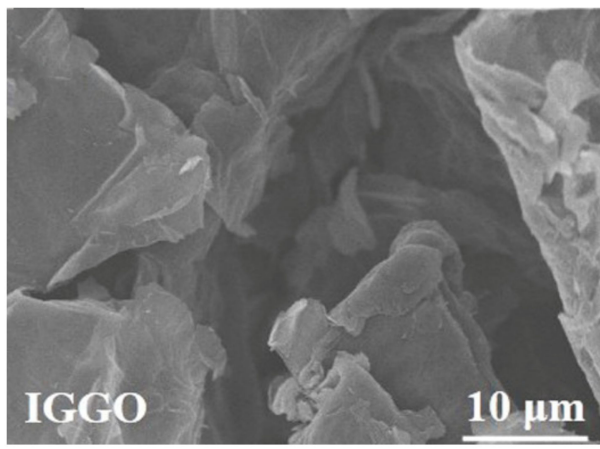

(b)

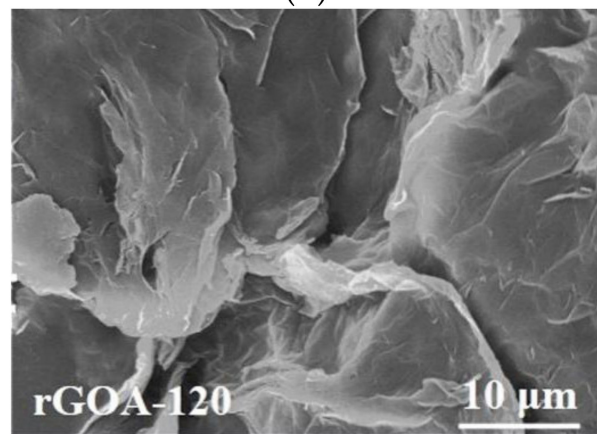

(d)

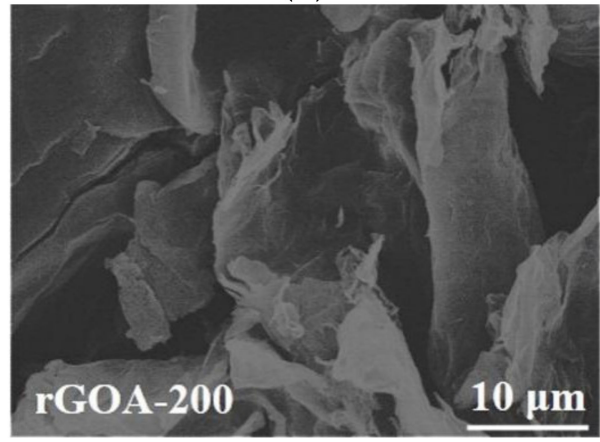

(f)

Figure 5. SEM images of IGGO (a,b), rGOA-120(c,d) and rGOA-200 (e,f).

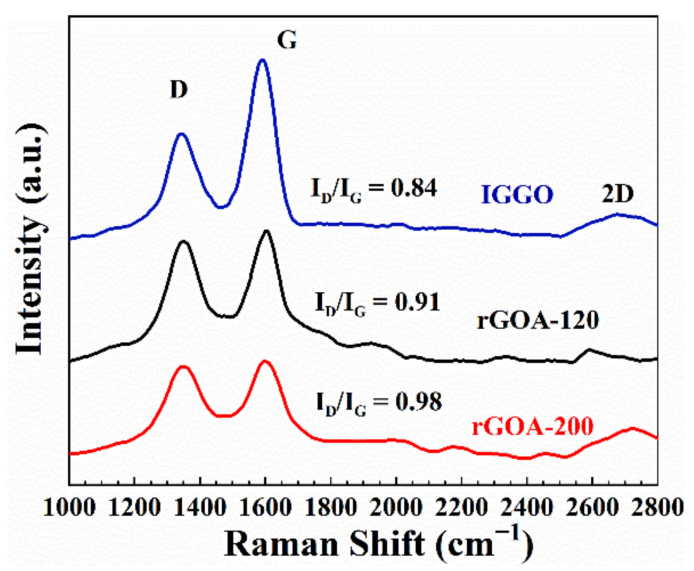

Figure 6. Raman spectra of IGGO, rGOA-120 and rGOA-200. 


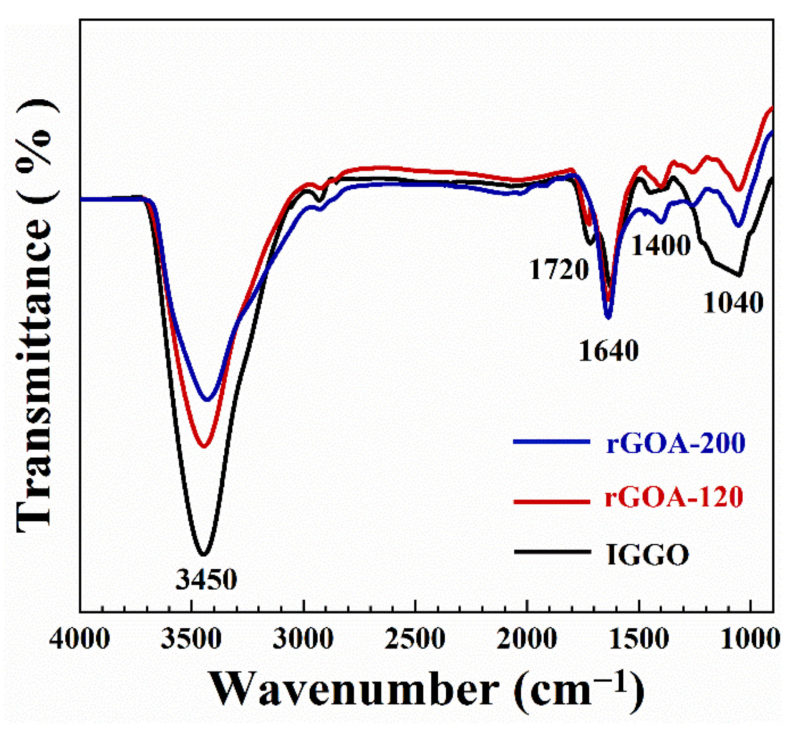

Figure 7. FTIR spectra of IGGO, rGOA-120 and rGOA-200.

\subsection{Comparison of the Dynamic Adsorption Performances of Different $r G O A s$}

L2 was chosen as a representative siloxane impurity in biogas to assess the adsorption and regeneration performances of the adsorbents.

Figure 8 shows the adsorption breakthrough curves obtained at $20{ }^{\circ} \mathrm{C}$ for L2 with IGGO and the five rGOA materials (the inlet concentration: $C_{\text {in }}=38.3 \mathrm{mg} \cdot \mathrm{L}^{-1}$; the gas flow rate: $\left.V_{\mathrm{q}}=0.01 \mathrm{~L} \cdot \mathrm{min}^{-1}\right)$. The corresponding dynamic adsorption parameters $\left(t_{\mathrm{B}}, Q_{\mathrm{B}}\right.$ and $Q_{\mathrm{m}}$ ) calculated from these isotherm curves are given in Table 2. Compared with IGGO, which had a very low removal efficiency for $\mathrm{L} 2$, the breakthrough curves obtained with each rGOA were progressively shifted towards increased time with increasing hydrothermal temperature. Consequently, the parameters $t_{\mathrm{B}}, Q_{\mathrm{B}}$ and $Q_{\mathrm{m}}$ also increased with increasing temperature, with rGOA-200 demonstrating the highest adsorption capacity $\left(t_{\mathrm{B}}=6.5 \mathrm{~min}\right.$; $\left.Q_{\mathrm{B}}=24.7 \mathrm{mg} \cdot \mathrm{g}^{-1} ; Q_{\mathrm{m}}=27.4 \mathrm{mg} \cdot \mathrm{g}^{-1}\right)$. These trends were consistent with those obtained from the $\mathrm{N}_{2}$ physisorption measurements $\left(S_{\mathrm{BET}}, V_{\text {micro }}\right)$ and contact angle analysis of the adsorbents (see Table 1). Figure 9a-d show the relationships between $Q_{\mathrm{B}}$ and the surface texture/hydrophobicity parameters $S_{\mathrm{BET}}, V_{\text {micro }}, V_{\text {tot }}$ and contact angle for the six adsorbents, respectively. Inspection of the linear correlation coefficients $\left(\mathrm{R}^{2}\right)$ for each fitted line showed that $S_{\text {BET }}\left(\mathrm{R}^{2}=0.97 ; p<0.05\right)$ and $V_{\text {micro }}\left(\mathrm{R}^{2}=0.89 ; p<0.05\right)$ were significantly associated with $Q_{\mathrm{B}}$, indicating that these were important parameters for the adsorption of L2. Since $S_{\mathrm{BET}}$ is theoretically dependent on the abundance of micropores/mesopores in the structure, it may be inferred that the mechanism of adsorption of L2 on rGOAs may be dependent on capillary condensation and hydrophobic effects [16-18].

Table 2. Adsorption parameters of the adsorbents for L2.

\begin{tabular}{cccc}
\hline Adsorbent & $\boldsymbol{t}_{\mathbf{B}}{ }^{\mathbf{1}}, \mathbf{m i n}$ & $\boldsymbol{Q}_{\mathbf{B}}{ }^{\mathbf{2}}, \mathbf{m g} \cdot \mathbf{g}^{-\mathbf{1}}$ & $\boldsymbol{Q}_{\mathbf{m}}{ }^{\mathbf{3}}, \mathbf{m g} \cdot \mathbf{g}^{-\mathbf{1}}$ \\
\hline IGGO & 1.1 & 4.4 & 7.1 \\
rGOA-100 & 1.8 & 7.2 & 10.5 \\
rGOA-120 & 3.0 & 12.3 & 14.1 \\
rGOA-140 & 5.8 & 22.5 & 24.3 \\
rGOA-160 & 6.0 & 23.1 & 25.4 \\
rGOA-200 & 6.5 & 24.7 & 27.4 \\
\hline
\end{tabular}

${ }^{1}$ Breakthrough time $\left(t_{\mathrm{B}}, \mathrm{min}\right) .{ }^{2}$ The L2 breakthrough adsorption capacity at $t_{\mathrm{B}}\left(Q_{\mathrm{B}}, \mathrm{mg} \cdot \mathrm{g}^{-1}\right) .{ }^{3}$ The $\mathrm{L} 2$ adsorption capacity at saturation $\left(Q_{\mathrm{m}}, \mathrm{mg} \cdot \mathrm{g}^{-1}\right)$. 


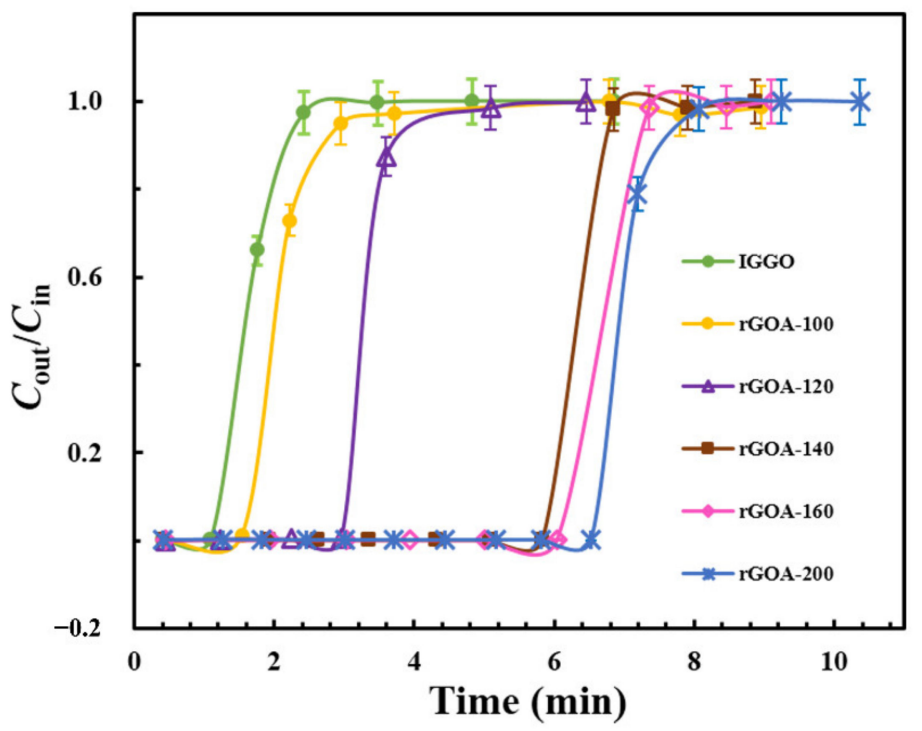

Figure 8. Breakthrough curves of the adsorbents for L2.

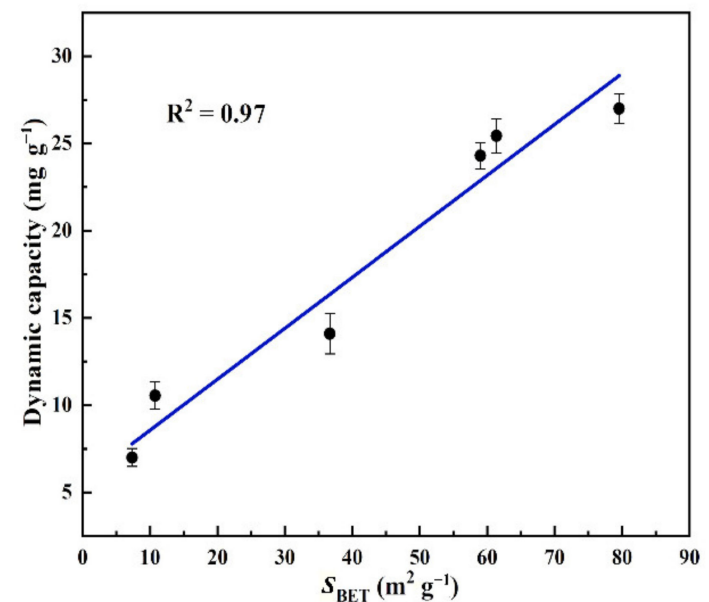

(a)

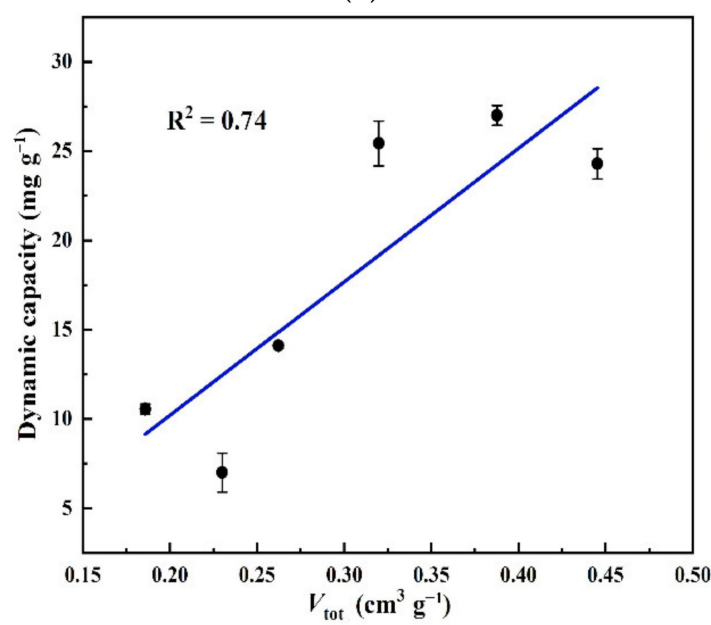

(c)

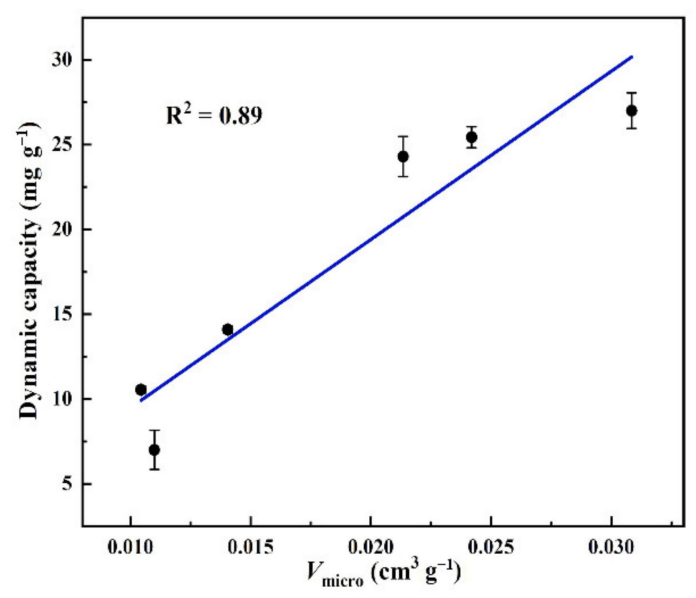

(b)

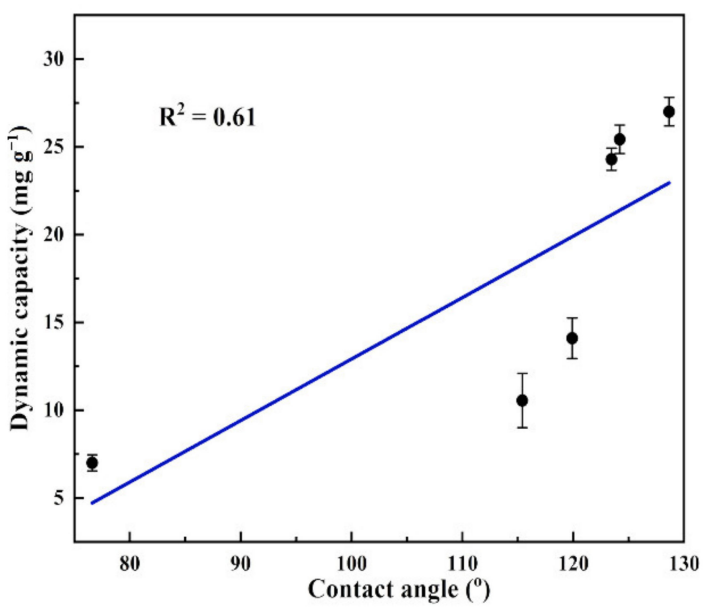

(d)

Figure 9. Relationships between $Q_{\mathrm{B}}$ and $S_{\mathrm{BET}}(\mathbf{a}), Q_{\mathrm{B}}$ and $V_{\text {tot }}(\mathbf{b}), Q_{\mathrm{B}}$ and $V_{\text {micro }}(\mathbf{c})$ and $Q_{\mathrm{B}}$ and contact angle (d) for the six adsorbents. 


\subsection{Influences of Process Conditions on the Adsorption Performance of $r G O A-200$}

An understanding of the correlation between the breakthrough time and inlet concentration is important for the industrial application of adsorbents $[12,14,18,44]$. Figure 10 shows the experimental relationship between $t_{\mathrm{B}}$ and $C_{\mathrm{in}}$ from the adsorption of L2 by rGOA-200 and the simulated curve fitting the experimental data. The results showed that there was a significant negative association between $t_{B}$ and $C_{\text {in }}\left(R^{2}=0.97, p<0.05\right)$, and the relationship could be reliably predicted by Equation (1). This provided a theoretical basis for potential industrial applications involving siloxane purification.

$$
t_{\mathrm{B}}=10.836 \times \mathrm{e}^{-\frac{c_{\text {in }}}{71}}
$$

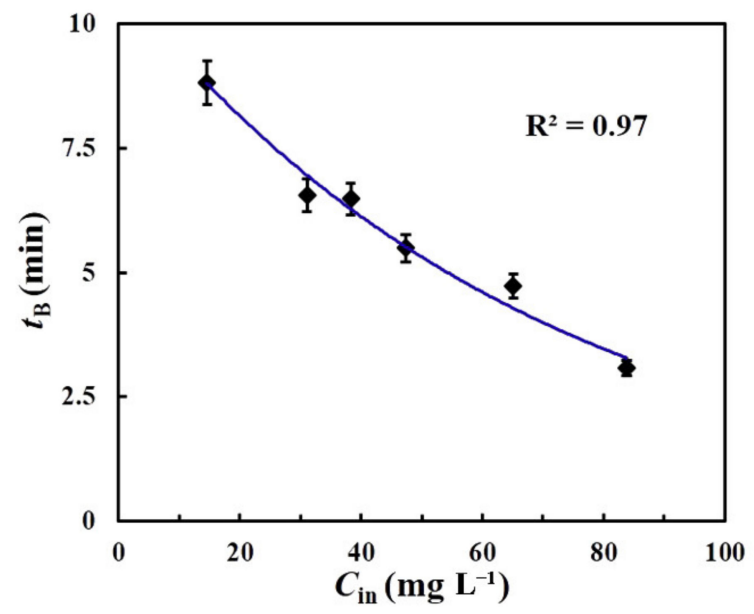

Figure 10. The effect of inlet concentration on breakthrough time.

The influence of bed temperature on L2 adsorption by rGOA-200 is given in Table 3. As the temperature decreased, $t_{\mathrm{B}}, Q_{\mathrm{B}}$ and $Q_{\mathrm{m}}$ increased, demonstrating that siloxane adsorption performance by rGOA-200 could be attained at low temperatures. This observation could be explained by the exothermic micropore filling and hydrophobic effects of the rGOA materials $[22,28,45]$. Hence, lowering the temperature would promote both mechanisms.

Table 3. Adsorption properties of rGOA-200 at different temperatures.

\begin{tabular}{ccccc}
\hline Entry & Temp., $^{\circ} \mathbf{C}$ & $\boldsymbol{t}_{\mathbf{B}}, \mathbf{m i n}$ & $\boldsymbol{Q}_{\mathbf{B}}, \mathbf{m g} \cdot \mathbf{g}^{-\mathbf{1}}$ & $\boldsymbol{Q}_{\mathbf{m}}, \mathbf{m g} \cdot \mathbf{g}^{-\mathbf{1}}$ \\
\hline 1 & 0 & 8.0 & 30.1 & 31.8 \\
2 & 10 & 6.5 & 24.6 & 26.0 \\
3 & 20 & 5.6 & 21.3 & 22.9 \\
4 & 30 & 4.9 & 18.6 & 20.0 \\
5 & 40 & 4.9 & 18.4 & 19.0 \\
6 & 50 & 4.5 & 17.3 & 18.8 \\
\hline
\end{tabular}

\subsection{Recycling Performance of $r G O A-200$}

L2 saturated rGOA-200 adsorbent could be regenerated by a simple heat-treatment at $100{ }^{\circ} \mathrm{C}$ for $30 \mathrm{~min}$. Figure 11 shows the results obtained from five L2 adsorption-desorption cycles, and Figure S2 shows that there was no residual L2 on the rGOA-200 after continuous cycles. The performance of rGOA-200 was almost consistent after each cycle, indicating that it had good reusability, mainly due to the physical adsorption mechanism. As can be seen from Table 4, although the adsorption capacity of rGOA remained lower than those of several carbon-based materials, its regeneration performance was the highest, with a more than $99 \%$ regeneration efficiency. 


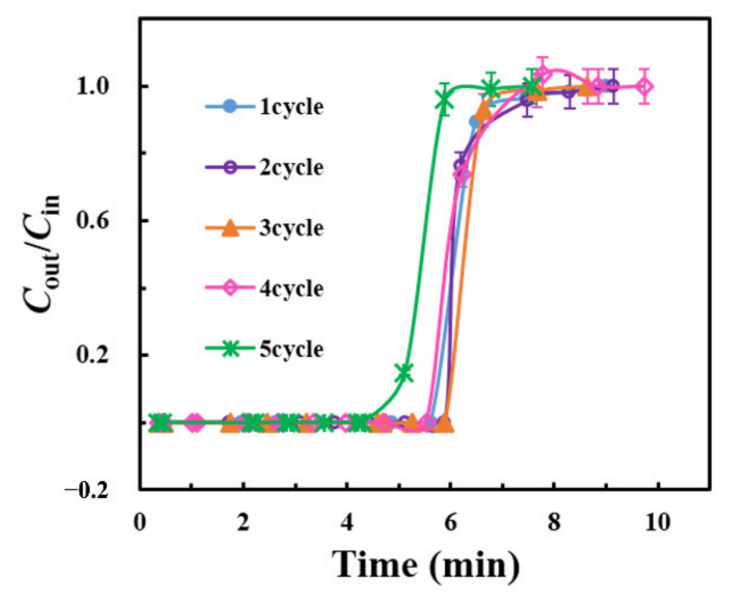

Figure 11. Adsorption breakthrough curves for L2 of rGOA-200 in the repeated cycles.

Table 4. Adsorption and regeneration capacities of different carbon materials for siloxanes.

\begin{tabular}{ccccc}
\hline Adsorbent & $\mathbf{Q}_{\mathbf{m}}, \mathbf{m g} \cdot \mathbf{g}^{-\mathbf{1}}$ & $\mathbf{R E}^{\mathbf{a}}, \mathbf{\%}$ & Regeneration Method & Reference \\
\hline $\begin{array}{c}\text { Activated } \\
\text { carbons }\end{array}$ & $10-100$ & $70-80$ & Four-step heating treatment at & $80-160{ }^{\circ} \mathrm{C}$ \\
$\begin{array}{c}\text { Activated } \\
\text { carbons }\end{array}$ & $60-878$ & 50 & Heating at $100-200{ }^{\circ} \mathrm{C}$ & {$[47]$} \\
$\begin{array}{c}\text { Activated } \\
\text { carbons }\end{array}$ & 526 & $40-92$ & Advanced oxidation processes & {$[48]$} \\
rGOA-200 & 32 & $>99$ & Heating at $100{ }^{\circ} \mathrm{C}$ & This work \\
\hline a & & &
\end{tabular}

\section{Experimental Section}

\subsection{Materials}

All reagents were purchased from commercial suppliers and used without further purification. IGGO was obtained from Hengqiu Graphene Technology Co., Ltd. (Suzhou, China). Hydrochloric acid (36 wt \%) was from Beijing Chemical Reagent Company (Beijing, China). Tert-butanol (99.7 wt\%) was from Yongda Chemical Co., Ltd. (Shandong, China). L2 (99 wt\%) was from Aladdin (Shanghai, China).

\subsection{Preparation of rGOA Adsorbents}

IGGO powder $(0.6 \mathrm{~g})$ was dispersed in hydrochloric acid $\left(60 \mathrm{~mL}\right.$ of $\left.0.1 \mathrm{~mol} \cdot \mathrm{L}^{-1}\right)$ for $1 \mathrm{~h}$, washed thoroughly (deionized water) and reconstituted in deionized water to obtain a $10 \mathrm{mg} \cdot \mathrm{mL}^{-1}$ dispersion. The IGGO dispersion was then sonicated for $1 \mathrm{~h}$ prior to sealing aliquots $(60 \mathrm{~mL})$ into polytetrafluoroethylene lined containers $(80 \mathrm{~mL})$ and subjecting them to hydrothermal treatments at $80,100,120,140,160$ and $200{ }^{\circ} \mathrm{C}$ for $16 \mathrm{~h}$ in a thermostatic oven [36]. IGGO dispersions formed hydrogels after hydrothermal treatments of $>80^{\circ} \mathrm{C}$. To protect the pore structure of the hydrogel, the material was soaked in tert-butanol for $6 \mathrm{~h}$ and pre-frozen prior to lyophilization $(<20 \mathrm{~Pa}, 24 \mathrm{~h})$ [49-51]. The resultant adsorbents were labelled rGOA-x, where $x$ represented the hydrothermal temperature.

\subsection{Characterization of IGGO and $r G O A-x$}

Surface morphology analysis of the adsorbents was performed using a S-4800 scanning electron microscope (SEM; Hitachi, Tokyo, Japan) and a transmission electron microscope (TEM, Hitachi, Tokyo, Japan) operated at $120 \mathrm{kV}$. The $\mathrm{N}_{2}$ adsorption-desorption isotherms were obtained from out-gassed samples $\left(95^{\circ} \mathrm{C}\right.$ for $12 \mathrm{~h}$ ) at $-196^{\circ} \mathrm{C}$ using a Kubo $\times 1000$ highperformance micropore analyzer (Beijing Builder Co., Ltd., Beijing, China) with the precision of $0.001 \mathrm{~m}^{2} \cdot \mathrm{g}^{-1}$. $S_{\mathrm{BET}}, V_{\text {tot }}$ and $V_{\text {micro }}$ were calculated according to the Brunauer-EmmettTeller (BET) and Dubinin-Radushkevich equations. The $\mathrm{D}_{\text {aver }}$ was obtained as $4 V_{\text {tot }} / S_{\mathrm{BET}}$, based on the BET method at a relative pressure $\left(P / P_{0}\right)$ range of $10^{-5}<P / P_{0}<0.98$ [52]. The 
X-ray diffraction (XRD) spectra were obtained using a D8 Advance X-ray diffractometer (Brucker AXS, Karlsruhe, Germany). Raman spectra were obtained with a $514 \mathrm{~nm}$ excitation wavelength on an inVia ${ }^{\mathrm{TM}}$ Raman spectrometer (Renishaw, New Mills, UK). Elemental analyses of $\mathrm{C}, \mathrm{H}$, and $\mathrm{N}$ was performed on a Vario EL III elemental analyzer (Elementar, Langenselbold, Germany). The Fourier transform infrared (FTIR) spectra (KBr pellet method) were acquired on a Nicolet 6700 spectrometer (Theromo Fisher, Waltham, MA, USA). The contact angle was obtained from a water drop $(3 \mu \mathrm{L})$ at room temperature using a JY-PHb contact angle/interface system (Jinhe Instrumentation, Nanjing, Jiangsu, China) and the sample was uniformly placed in the edge of the glass substrate with the thickness $<0.1 \mathrm{~mm}$. L2 concentration in the gas stream was measured using a 9790 gas chromatography system equipped with a flame ionization detector (GC-FID; Zhejiang Fuli Analytical Instrument Co., Ltd., Wenling, Zhejiang, China). Separation was carried out isothermally $\left(200{ }^{\circ} \mathrm{C}\right)$ on a $2.0 \mathrm{~m} \times 2.0 \mathrm{~mm}$ I.D. column packed with poly divinylbenzene porous beads (GDX-102, Aladdin, Shanghai, China) using $\mathrm{N}_{2}$ carrier gas $\left(30 \mathrm{~mL} \cdot \mathrm{min}^{-1}\right)$.

\subsection{L2 Adsorption-Desorption Behavior}

Dynamic gas adsorption tests were carried out on $0.1 \mathrm{~g}$ of adsorbent with $0.2 \mathrm{~g}$ of pine chips mixed in evenly at $20^{\circ} \mathrm{C}$; the inlet concentration of $\mathrm{L} 2$ was $38.28 \mathrm{mg} \cdot \mathrm{L}^{-1}$ at a total gas flow rate of $0.01 \mathrm{~L} \cdot \mathrm{min}^{-1}$. The system was operated until the outlet concentration $\left(C_{\text {out }, t}\right)$ was equal to the inlet concentration $\left(C_{\text {in }}\right)$, i.e., when the system had attained adsorption saturation, and the corresponding breakthrough curves were obtained by plotting $C_{\text {out }, t} / C_{\text {in }}$ versus $t$. Adsorbent performance was evaluated by the following indicators: (i) breakthrough time $\left(t_{\mathrm{B}}, \mathrm{min}\right)$, defined by $C_{\mathrm{out}, t} / C_{\mathrm{in}}=0.05$; (ii) the $\mathrm{L} 2$ breakthrough adsorption capacity at $t_{\mathrm{B}}\left(Q_{\mathrm{B}}, \mathrm{mg} \cdot \mathrm{g}^{-1}\right)$; and (iii) the $\mathrm{L} 2$ adsorption capacity at saturation $\left(Q_{\mathrm{m}}, \mathrm{mg} \cdot \mathrm{g}^{-1}\right)$. $Q_{B}$ and $Q_{m}$ were calculated from Equation (2) [16]:

$$
Q_{t}=\frac{V_{q} C_{\text {in }}}{m} \int_{0}^{t}\left(1-\frac{C_{\text {out }, t}}{C_{\text {in }}}\right) d t
$$

where $V_{\mathrm{q}}$ was the gas flow rate $\left(\mathrm{L} \cdot \mathrm{min}^{-1}\right), m$ was the adsorbent weight $(\mathrm{g}), C_{\text {in }}$ was the inlet concentration $\left(\mathrm{mg} \cdot \mathrm{L}^{-1}\right)$ and $C_{\mathrm{out}, t}$ was the outlet concentration $\left(\mathrm{mg} \cdot \mathrm{L}^{-1}\right)$ at an adsorption time $t$ ( $\mathrm{min}$ ). According to this equation, a fixed time point $t$ corresponded to a unique $Q_{t}$. When $t$ was equal to $t_{\mathrm{B}}, Q_{\mathrm{B}}$ could be obtained. Similarly, when $t$ corresponded to the saturation point, i.e., where $C_{\text {out }, t} / C_{\text {in }} \approx 1, Q_{\mathrm{m}}$ could be obtained.

Desorption characteristics were determined by heating the saturated sample in situ at $100{ }^{\circ} \mathrm{C}$ for 30 min under continuous $\mathrm{N}_{2}$ purge and monitoring the residual concentration of L2 by GC-FID. A total of five adsorption-desorption cycles were carried out to determine the recycling performance of the adsorbent.

\section{Conclusions}

A series of hydrophobic and porous rGOA materials were successfully prepared from IGGO using a simple hydrothermal method. Surface morphology analysis showed that the rGOAs had a macroporus 3D network structure. Spectroscopic analysis (XRD, FTIR, Raman) confirmed a non-crystalline nature and attenuation of oxygen-containing groups following the reduction of IGGO to rGOAs. The $S_{\mathrm{BET}}, V_{\text {micro }}$ and water contact angle of each rGOA increased with increasing hydrothermal temperature treatment of IGGO. Adsorption breakthrough experiments revealed that the adsorptive performance of the rGOAs for L2 increased with increasing hydrothermal treatment temperature. $Q_{\mathrm{B}}$ showed a significant linear association with $S_{\mathrm{BET}}\left(\mathrm{R}^{2}=0.97, p<0.05\right)$ and $V_{\text {micro }}\left(\mathrm{R}^{2}=0.89, p<0.05\right)$, indicating that they were important parameters for the adsorption of L2. rGOA-200 exhibited the highest adsorption of all rGOAs towards $\mathrm{L} 2$ at $20^{\circ} \mathrm{C}\left(t_{\mathrm{B}}=6.5 \mathrm{~min}, Q_{\mathrm{B}}=24.7 \mathrm{mg} \cdot \mathrm{g}^{-1}\right.$, $\left.Q_{\mathrm{m}}=27.4 \mathrm{mg} \cdot \mathrm{g}^{-1}\right)$. Values of $t_{\mathrm{B}}, Q_{\mathrm{B}}$ and $Q_{\mathrm{m}}$ all increased with decreasing bed temperature. Saturated rGOA-200 was readily regenerated by a brief heat-treatment at $100{ }^{\circ} \mathrm{C}$. 
Supplementary Materials: The following are available online, Figure S1: TEM images of rGOA-200 and IGGO, Figure S2: FTIR spectra of samples processed by different treatments, Table S1: Elemental contents of IGGO, rGOA-120, rGOA-200.

Author Contributions: X.H., Y.Z. and X.M. performed the experimental investigation. X.H. and Y.Z. performed the data curation and the analysis and wrote the first draft of the manuscript. Y.L. performed the writing - review and editing. Z.M. performed the writing-review, the editing, the project administration and the funding acquisition. All authors have read and agreed to the published version of the manuscript.

Funding: This study was supported by the National Natural Science Foundation of China (21677046) and the Natural Science Foundation of Hebei Province (B2017205146).

Data Availability Statement: Data is contained within the article or supplementary materials. The data presented in this study are available in Supplementary Materials.

Conflicts of Interest: The authors declare no conflict of interest.

Sample Availability: Samples of the compounds IGGO and rGOAs are available from the authors.

\section{References}

1. De Arespacochaga, N.; Valderrama, C.; Raich, J.; Crest, M.; Mehta, S.; Cortina, J.L. Understanding the effects of the origin, occurrence, monitoring, control, fate and removal of siloxanes on the energetic valorization of sewage biogas-A review. Renew. Sustain. Energy Rev. 2015, 52, 366-381. [CrossRef]

2. Rücker, C.; Kümmerer, K. Environmental chemistry of organosiloxanes. Chem. Rev. 2014, 115, 466-524. [CrossRef]

3. Talle, M.; Wirehn, L.; Ellstrom, D.; Hjerpe, M.; Huge-Brodin, M.; Jensen, P.; Lindstrom, T.; Neset, T.S.; Wennergren, U.; Metson, G. Synergies and trade-offs for sustainable food production in Sweden: An integrated approach. Sustainability 2019, $11,601$. [CrossRef]

4. Korys, K.A.; Latawiec, A.E.; Grotkiewicz, K.; Kubon, M. The review of biomass potential for agricultural biogas production in Poland. Sustainability 2019, 11, 6515. [CrossRef]

5. Kajolinna, T.; Aakko-Saksa, P.; Roine, J.; Kall, L. Efficiency testing of three biogas siloxane removal systems in the presence of D5, D6, limonene and toluene. Fuel Process. Technol. 2015, 139, 242-247. [CrossRef]

6. Zabed, H.M.; Akter, S.; Yun, J.; Zhang, G.; Awad, F.N.; Qi, X.; Sahu, J.N. Recent advances in biological pretreatment of microalgae and lignocellulosic biomass for biofuel production. Renew. Sustain. Energy Rev. 2019, 105, 105-128. [CrossRef]

7. Li, Y.; Chen, Y.; Wu, J. Enhancement of methane production in anaerobic digestion process: A review. Appl. Energy 2019, 240, 120-137. [CrossRef]

8. Xiong, X.; Yu, I.K.M.; Tsang, D.C.W.; Bolan, N.S.; Ok, Y.S.; Igalavithana, A.D.; Kirkham, M.B.; Kim, K.H.; Vikrant, K. Value-added chemicals from food supply chain wastes: State-of-the-art review and future prospects. Chem. Eng. J. 2019, 375, 1900807. [CrossRef]

9. Bharadwaz, A.; Jayasuriya, A.C. Recent trends in the application of widely used natural and synthetic polymer nanocomposites in bone tissue regeneration. Mat. Sci. Eng. C Mater. 2020, 110, 110698. [CrossRef] [PubMed]

10. Huang, X.X.; Shen, T.; Zhang, T.; Qiu, H.L.; Gu, X.X.; Ali, Z.; Hou, Y.L. Efficient oxygen reduction catalysts of porous carbon nanostructures decorated with transition metal species. Adv. Energy Mater. 2020, 10, 1900375. [CrossRef]

11. Nam, S.; Namkoong, W.; Kang, J.H.; Park, J.K.; Lee, N. Adsorption characteristics of siloxanes in landfill gas by the adsorption equilibrium test. Waste Manag. 2013, 33, 2091-2098. [CrossRef] [PubMed]

12. Jiang, T.; Zhong, W.; Jafari, T.; Du, S.C.; He, J.K.; Fu, Y.J.; Singh, P.; Suib, S.L. Siloxane D4 adsorption by mesoporous aluminosilicates. Chem. Eng. J. 2016, 289, 356-364. [CrossRef]

13. Santiago, R.; Moya, C.; Palomar, J. Siloxanes capture by ionic liquids: Solvent selection and process evaluation. Chem. Eng. J. 2020, 401, 126078. [CrossRef]

14. Cabrera-Codony, A.; Montes-Moran, M.A.; Sanchez-Polo, M.; Martin, M.J.; Gonzalez-Olmos, R. Biogas upgrading: Optimal activated carbon properties for siloxane removal. Environ. Sci. Technol. 2014, 48, 7187-7195. [CrossRef]

15. Mahmoudi, E.; Azizkhani, S.; Mohammad, A.W.; Ng, L.Y.; Benamor, A.; Ang, W.L.; Ba-Abbad, M. Simultaneous removal of Congo red and cadmium (II) from aqueous solutions using graphene oxide-Silica composite as a multifunctional adsorbent. J. Environ. Sci. 2020, 98, 151-160. [CrossRef]

16. Meng, Z.Y.; Liu, Y.H.; Li, X.; Ma, Z.C. Removal of siloxane (L2) from biogas using methyl-functionalised silica gel as adsorbent. Chem. Eng. J. 2020, 389, 124440. [CrossRef]

17. Meng, Z.Y.; Liu, Y.H.; Ma, Z.C.; Hou, X.F. The regulation of micro/mesoporous silica gel by polyethylene imine for enhancing the siloxane removal. Inorg. Chem. Commun. 2020, 112, 107754. [CrossRef]

18. Liu, Y.H.; Meng, Z.Y.; Wang, J.Y.; Dong, Y.F.; Ma, Z.C. Removal of siloxanes from biogas using acetylated silica gel as adsorbent. Petrol. Sci. 2019, 16, 920-928. [CrossRef] 
19. Hu, J.S.; Zhang, P.F.; Cui, J.F.; An, W.J.; Liu, L.; Liang, Y.H.; Yang, Q.B.; Yang, H.J.; Cui, W.Q. High-efficiency removal of phenol and coking wastewater via photocatalysis-Fenton synergy over a Fe-g- $\mathrm{C}_{3} \mathrm{~N}_{4}$ graphene hydrogel $3 \mathrm{D}$ structure. J. Ind. Eng. Chem. 2020, 84, 305-314. [CrossRef]

20. Lu, J.R.; Wu, X.N.; Li, Y.; Liang, Y.H.; Cui, W.Q. Facile fabrication of 3D graphene-silica hydrogel composite for enhanced removal of mercury ions. Nanomaterials 2019, 9, 314. [CrossRef]

21. Li, X.L.; Wang, X.J.; Zhu, J.Y.; Li, Y.P.; Zhao, J.; Li, F.T. Fabrication of two-dimensional $\mathrm{Ni}_{2} \mathrm{P} / \mathrm{ZnIn}_{2} \mathrm{~S}_{4}$ heterostructures for enhanced photocatalytic hydrogen evolution. Chem. Eng. J. 2018, 353, 15-24. [CrossRef]

22. Li, Y.P.; Li, F.T.; Wang, X.J.; Zhao, J.; Wei, J.N.; Hao, Y.J.; Liu, Y. Z-scheme electronic transfer of quantum-sized alpha-Fe ${ }_{2} \mathrm{O}_{3}$ modified $\mathrm{g}-\mathrm{C}_{3} \mathrm{~N}_{4}$ hybrids for enhanced photocatalytic hydrogen production. Int. J. Hydrog. Energy 2017, 42, 28327-28336. [CrossRef]

23. Noroozi, A.R.; Malekzadeh, P.; Dimitri, R.; Tornabene, F. Meshfree radial point interpolation method for the vibration and buckling analysis of FG-GPLRC perforated plates under an in-plane loading. Eng. Struct. 2020, 221, 111000. [CrossRef]

24. Hruby, J.; Santana, V.T.; Kostiuk, D.; Boucek, M.; Lenz, S.; Kern, M.; Siffalovic, P.; van Slageren, J.; Neugebauer, P. A graphenebased hybrid material with quantum bits prepared by the double langmuir-schaefer method. RSC Adv. 2019, 9, 24066-24073. [CrossRef]

25. Zhang, Y.N.; Niu, Q.Y.; Gu, X.T.; Yang, N.; Zhao, G.H. Recent progress on carbon nanomaterials for the electrochemical detection and removal of environmental pollutants. Nanoscale 2019, 11, 11992-12014. [CrossRef]

26. Feng, D.D.; Wang, S.Z.; Zhang, Y.; Zhao, Y.J.; Sun, S.Z.; Chang, G.Z.; Lai, X.Y.; Tan, H.P.; Qin, Y.K. Review of carbon fixation evaluation and emission reduction effectiveness for biochar in China. Energy Fuel. 2020, 34, 10583-10606. [CrossRef]

27. Bi, H.C.; Yin, K.B.; Xie, X.; Zhou, Y.L.; Wan, N.; Xu, F.; Banhart, F.; Sun, L.T.; Ruoff, R.S. Low temperature casting of graphene with high compressive strength. Adv. Mater. 2012, 24, 5124-5129. [CrossRef]

28. Xie, Y.H.; Sheng, X.X.; Xie, D.L.; Liu, Z.X.; Zhang, X.Y.; Zhong, L. Fabricating graphene hydrogels with controllable pore structure via one-step chemical reduction process. Carbon 2016, 109, 673-680. [CrossRef]

29. Arshid, H.; Khorasani, M.; Soleimani-Javid, Z.; Dimitri, R.; Tornabene, F. Quasi-3D hyperbolic shear deformation theory for the free vibration study of honeycomb microplates with graphene nanoplatelets-reinforced epoxy skins. Molecules 2020, 25,5085 [CrossRef]

30. Zhou, Y.; Bao, Q.; Tang, L.A.L.; Zhong, Y.; Loh, K.P. Hydrothermal dehydration for the "green" reduction of exfoliated graphene oxide to graphene and demonstration of tunable optical limiting properties. Chem. Mater. 2009, 21, 2950-2956. [CrossRef]

31. Shi, Y.C.; Feng, J.J.; Lin, X.X.; Zhang, L.; Yuan, J.H.; Zhang, Q.L.; Wang, A.J. One-step hydrothermal synthesis of three-dimensional nitrogen-doped reduced graphene oxide hydrogels anchored PtPd alloyed nanoparticles for ethylene glycol oxidation and hydrogen evolution reactions. Electrochim. Acta 2019, 293, 504-513. [CrossRef]

32. Sui, Z.Y.; Zhang, X.T.; Lei, Y.; Luo, Y.J. Easy and green synthesis of reduced graphite oxide-based hydrogels. Carbon 2011, 49, 4314-4321. [CrossRef]

33. Liang, S.; Zhou, Z.; Wu, X.; Zhu, S.; Bi, J.; Zhou, L.; Liu, M.; Wu, L. Constructing a MoS 2 QDs/CdS core/shell flowerlike nano sphere hierarchical heterostructure for the enhanced stability and photocatalytic activity. Molecules 2016, 21, 213. [CrossRef] [PubMed]

34. Li, X.Q.; Zhang, L.; Yang, Z.Q.; Wang, P.; Yan, Y.F.; Ran, J.Y. Adsorption materials for volatile organic compounds (VOCs) and the key factors for VOCs adsorption process: A review. Sep. Purif. Technol. 2020, 235, 116213. [CrossRef]

35. Korkmaz, S.; Kariper, I.A. Graphene and graphene oxide based aerogels: Synthesis, characteristics and supercapacitor applica tions. J. Energy Storage 2020, 27, 101038. [CrossRef]

36. Zuo, L.Z.; Zhang, Y.F.; Zhang, L.S.; Miao, Y.E.; Fan, W.; Liu, T.X. Polymer/carbon-based hybrid aerogels: Preparation, properties and applications. Materials 2015, 8, 6806-6848. [CrossRef] [PubMed]

37. Yu, J.M.; Huang, T.Z.; Jiang, Z.K.; Sun, M.; Tang, C.C. Synthesis and characterizations of zinc oxide on reduced graphene oxide for high performance electrocatalytic reduction of oxygen. Molecules 2018, 23, 3227. [CrossRef] [PubMed]

38. Sui, Z.Y.; Han, B.H. Effect of surface chemistry and textural properties on carbon dioxide uptake in hydrothermally reduced graphene oxide. Carbon 2015, 82, 590-598. [CrossRef]

39. Xu, Y.; Sheng, K.; Li, C.; Shi, G.J.A.N. Self-assembled graphene hydrogel via a one-step hydrothermal process. ACS Nano 2010, 4, 4324-4330. [CrossRef] [PubMed]

40. Sui, Z.Y.; Wang, C.; Yang, Q.-S.; Shu, K.; Liu, Y.-W.; Han, B.H.; Wallace, G.G. A highly nitrogen-doped porous graphene-An anode material for lithium ion batteries. J. Mater. Chem. A 2015, 3, 18229-18237. [CrossRef]

41. Hruby, J.; Vavreckova, S.; Masaryk, L.; Sojka, A.; Navarro-Giraldo, J.; Bartos, M.; Herchel, R.; Moncol, J.; Nemec, I.; Neugebauer, P. Deposition of tetracoordinate Co (II) complex with chalcone ligands on graphene. Molecules 2020, 25, 5021. [CrossRef] [PubMed]

42. Junaid, M.; Khir, M.H.M.; Witjaksono, G.; Tansu, N.; Saheed, M.S.M.; Kumar, P.; Ullah, Z.; Yar, A.; Usman, F. Boron-doped reduced graphene oxide with tunable bandgap and enhanced surface plasmon resonance. Molecules 2020, 25, 3646. [CrossRef]

43. Tran, T.V.; Nguyen, D.T.C.; Le, H.T.N.; Vo, D.V.N.; Nanda, S.; Nguyen, T.D. Optimization, equilibrium, adsorption behavior and role of surface functional groups on graphene oxide-based nanocomposite towards diclofenac drug. J. Environ. Sci. 2020, 93, 137-150. [CrossRef] [PubMed]

44. Oshita, K.; Ishihara, Y.; Takaoka, M.; Takeda, N.; Matsumoto, T.; Morisawa, S.; Kitayama, A. Behaviour and adsorptive removal of siloxanes in sewage sludge biogas. Water Sci. Technol. 2010, 61, 2003-2012. [CrossRef] [PubMed] 
45. Li, G.; Xu, C. Hydrothermal synthesis of $3 \mathrm{D} \mathrm{Ni}_{x} \mathrm{Co}_{1-\mathrm{x}} \mathrm{S}_{2}$ particles/graphene composite hydrogels for high performance supercapacitors. Carbon 2015, 90, 44-52. [CrossRef]

46. Gislon, P.; Galli, S.; Monteleone, G. Siloxanes removal from biogas by high surface area adsorbents. Waste Manag. 2013, 33, 2687-2693. [CrossRef]

47. Finocchio, E.; Montanari, T.; Garuti, G.; Pistarino, C.; Federici, F.; Cugino, M.; Busca, G. Purification of biogases from siloxanes by adsorption: On the regenerability of activated carbon sorbents. Energy Fuel 2009, 23, 4156-4159. [CrossRef]

48. Cabrera-Codony, A.; Gonzalez-Olmos, R.; Martín, M.J. Regeneration of siloxane-exhausted activated carbon by advanced oxidation processes. J. Hazard. Mater. 2015, 285, 501-508. [CrossRef] [PubMed]

49. Alipoorfard, F.; Jouki, M.; Tavakolipour, H. Application of sodium chloride and quince seed gum pretreatments to prevent enzymatic browning, loss of texture and antioxidant activity of freeze dried pear slices. J. Food Sci. Technol. 2020, 57, 3165-3175. [CrossRef]

50. Dadmohammadi, Y.; Datta, A.K. Food as porous media: A review of the dynamics of porous properties during processing. Food Rev. Int. 2020, 1-33. [CrossRef]

51. El-Naggar, M.E.; Othman, S.I.; Allam, A.A.; Morsy, O.M. Synthesis, drying process and medical application of polysaccharidebased aerogels. Int. J. Biol. Macromol. 2020, 145, 1115-1128. [CrossRef] [PubMed]

52. Li, K.; Chen, W.; Yang, H.; Chen, Y.; Xia, S.; Xia, M.; Tu, X.; Chen, H. Mechanism of biomass activation and ammonia modification for nitrogen-doped porous carbon materials. Bioresour. Technol. 2019, 280, 260-268. [CrossRef] [PubMed] 